\title{
二重課題条件が転倒経験者の障害物跨ぎにおける toe-obstacle distance に与える影響について \\ Influence of a dual-task condition on toe-obstacle distance of stepping over an obstacle by elderly people who had a fall experience in the past year.
}

\author{
相馬正之 $之^{11}$ 中江秀幸 ${ }^{11}$ 安彦鉄平 ${ }^{2}$ \\ 島 村亮 $太^{2)}$ 川間健之介 ${ }^{31}$
}

\author{
MASAYUKi SOMA,RPT,MS ${ }^{1)}$, HIDEYUKI NAKAE,RPT,MS ${ }^{1)}$, TEPPEI ABIKO,RPT,MS ${ }^{2)}$ \\ RYOTA SHIMAMURA,RPT,MS ${ }^{2)}$, KAWAMA KENNOSUKE PhD ${ }^{3)}$
}

\begin{abstract}
要旨: 本研究では, 二重課題条件が転倒経験者の障害物跨ぎにおける足部の踏み切り位置 と障害物間との距離（以下, toe-obstacle distance）に与える影響について検討した。対象 は, 若年群30名，65歳以上の高齢群30名とし，高齢群への聞き取り調査から高齡群を転倒 経験群 7 名, 非転倒経験群23名に分類した。設定課題は, 運動課題のみの単課題条件およ び運動課題中に認知課題を課す二重課題条件の 2 通りとした。運動課題は，対象者自身の 快適歩行で $9 \mathrm{~m}$ 歩行路の中間地点に設置された高さ $2 \mathrm{~cm}$ ，幅 $15 \mathrm{~cm}$ ，奥行き $80 \mathrm{~cm}$ の木製障害 物の跨ぎ動作とした。認知課題は，100から 7 を減じていく連続 7 減算とした。二元配置 分散分析の結果, toe-obstacle distance では, 対象群と歩行条件との間に有意な交互作用が 認められた。多重比較の結果，若年群および非転倒経験群の DT 条件は ST 条件に比べ有 意な差が認められなかったものの，転倒経駼群の DT 条件は ST 条件に比べ有意に低值を 示した。本結果から転倒経験群の toe-obstacle distance は，若年群および非転倒経験群と異 なっている可能性が示唆された。
\end{abstract}

キーワード : toe-obstacle distance 二重課題 転倒経験者

\begin{abstract}
The purpose of this study was to investigate the influence of a dual-task condition on toe-obstacle distance of stepping over an obstacle by elderly people who had a fall experience in the past year. The subjects were 30 young women and 30 community-dwelling elderly women. In addition, 30 community-dwelling elderly women were divided 7 people who had a history of falls and 23 people who had no history of falls in the past year by based on interview results. We measured stepping over parameter the single and dual tasks. The single task was a solitary motor task. The dual task consisted of a motor task and a concurrent cognitive task. The motor task was stepping over a $2-\mathrm{cm}$ high wooden obstacle that was $80 \mathrm{~cm}$ wide, and $15 \mathrm{~cm}$ deep, which was set up in
\end{abstract}

受付日：2011年 6 月16日，採択日：2011年 7 月28日

1 ) 東北福祉大学健康科学部リハビリテーション学科 Tohoku Fukushi university, Faculty of health sciences, Course of physical therapy Department of rehabilitation,

2 ) 東京都リハビリテーション病院 理学療法科 Tokyo metropolitan rehabilitation hospital, Division of physical therapy,

3 ) 筑波大学人間総合科学研究科

Institute of disability sciences, university of tsukuba E-mail: souma@tfu-mail.tfu.ac.jp 


\begin{abstract}
the middle of a 9-m walkway during comfortable gait, and the cognitive task was the serial subtraction of seven from 100. Two-way ANOVA showed that toe-obstacle distance had a significant interaction between the group and condition, and in elderly people group who had a fall experience, toeobstacle distance in dual tasks condition was significantly decreased contrasting by that in single task condition. These results suggest that young women, non-fallers and fallers may have different strategies fallers for stepping over an obstacle
\end{abstract}

I .はじめに

わが国における高齢者の転倒発生率は , 全体の約 $20 \%$ であり，弚の多くは歩行中のつまずきに起因する ことが報告されている(12)。光のため，障害物跨ぎ動作 に関する運動学的・運動力学的な視点から数多くの報 告が散見される ${ }^{3)-10) 。 そ ゙ の 中 て ゙ ~ P a t l a ~ ら ~}{ }^{1112}$ (は，障害物 への接近過程で得られる視覚情報に基づいた“跨ぎ” の下肢の運動軌跡が前もって計画されていることを報 告している。これらのことから，歩行中のつまずきを 防止するためには跨ぎ動作产のものではなく，跨ぎ動 作開始前の足部の踏み切り位置と障害物間との距離

(以下, toe-obstacle distance) が重要であると考えら れる。この toe-obstacle distance については, 障害物の 高さと関係なく，通常歩行の歩幅の $42 \sim 44 \%$ 程度であ $ろ^{13)}$ ことや，高齢者では若年者に比べて障害物からよ り遠くで跨ぐ傾向にあることが示されている゙”。

近年，易転倒傾向にある高齢者の場合，二重課題 (dual task : 以下 DT) 条件下において, 歩行時の注 意量が減少することにより，歩行課題の遂行能力に影 響を及ぼすことが明らかにされている ${ }^{14-20) 。 し か し ， ~}$ これらの DT 条件下での運動課題を障害物跨ぎと設定 して実施している報告は少ない(21)-22)。筆者ら ${ }^{21}$ は, 平 均69歳の地域在住高齢群と平均26歳の若年群を対象に， 運動課題を快適歩行速度下での障害物跨ぎ, 認知課題 を連続 7 減算の DT 条件と設定した結果, toe-obstacle distance には有意な差が認められなかったことを報告 した。また，Schrodt ら ${ }^{22}$ は, 平均73 4歳の地域在住 高齢者を対象に，運動課題を最速歩行下での障害物跨 ぎ, 認知課題を一定間隔で提示される数字のうち $1 つ$ 前に聞いた数字を答える1- back task の DT 条件と設 定した結果, toe-obstacle distance の減少か認められた と述べている。この2 つ結果の相違は, 運動課題と認 知課題の難易度に影響を受けるものと考えられる。し かし, これらの先行研究は, 高齢群と若年群との比較 や地域在住高齢者間での比較であり，易転倒傾向にあ る高齢者を対象とした報告は見当たらない。過去 1 年 間の転倒経験が, 光の後の転倒に対する強い予知因子 となることも報告 ${ }^{23)}$ されており，転倒経験者を易転倒
傾向の対象者と仮定すると DT 条件下において転倒経 験者では，障害物跨ぎ動作の踏み切り位置である toeobstacle distance に何らかの影響があることが予測され る。

弚こで本研究では, DT 条件が転倒経験者の障害物 跨ぎにおける toe-obstacle distance に与える影響につい て検討した。

\section{II . 対象および方法}

\section{1. 対 象}

対象は，両下肢に整形学的疾患の既往のない健常女 性30名を若年群，65歳以上の30名を高龄群とした。さ らに高齢群は, 過去 1 年以内における転倒の有無の聞 き取り調査を行い, 転倒経験の有無から非転倒経験群 23名, 転倒経験群 7 名に分類した (表 1 )。全ての対 象者に特別な運動習慣は認められなかった。なお，本 研究の転倒の定義は, Gibson ${ }^{24}$ による「自分の意思に よらず，足底以外の部分が床，地面に着いた場合」と し，階段，台，自転車からの転落などを除外した。転 倒経験群 7 名の転倒時の状況は，「段差などにつまず いた」が5名，「急いでいて足がもつれた」，「不整地 を歩いていてバランスを崩した」が各1名であった。

本研究は, 筑波大学院研究倫理委員会の承認を受け 実施した。また, 対象者には事前に本研究の目的を十 分に説明し，同意を得た上で実施した。

表 1 対象者の属性 $(\mathrm{n}=60)$

\begin{tabular}{|c|c|c|c|}
\hline & \multirow{2}{*}{ 若年群 } & \multicolumn{2}{|c|}{ 高齢群 } \\
\hline & & 非転倒経験群 & 転倒経験群 \\
\hline 対象者 (人) & 30 & 23 & 7 \\
\hline 年 齢 (歳) & $263 \pm 32$ & $\begin{array}{ll}* & 69.7 \pm 3.7 \\
\end{array}$ & $676 \pm 31$ \\
\hline 身 長 $(\mathrm{cm})$ & $1 5 7 2 \longdiv { \square . 4 }$ & * $1518 \pm 45$ & $1483 \pm 58$ \\
\hline 体 重 (kg) & $513 \pm 71$ & $528 \pm 82$ & $50.0 \pm 5.0$ \\
\hline 足 長 $(\mathrm{cm})$ & $228 \pm 1.0$ & $22.6 \pm 0.7$ & $21.9 \pm 11$ \\
\hline
\end{tabular}

\section{2. 方 法}

障害物を跨ぐ運動課題は, 運動課題のみの Single Task (以下, ST) 条件下および運動課題中に認知課 
題を課す DT 条件下の 2 通りとし，各 5 回施行した。 各施行間には，十分に時間を設けた。運動課題は，対 象者自身の快適歩行で $9 \mathrm{~m}$ 歩行路の中間地点に設置さ れた高さ $2 \mathrm{~cm}$ ，幅 $15 \mathrm{~cm}$ ，奥行き $80 \mathrm{~cm}$ の木製障害物を跨 ぐ動作とした。認知課題は，100から 7 を減ずる連続 7 減算とした。ST 条件下の運動課題遂行に関する説 明は，「普段歩き慣れている速さで，いつも通りに歩 き，障害物を跨いでください」と対象者に口頭で指示 した。また，DT 条件下では，「普段歩き慣れている 速さで，いつも通りに歩き，障害物を跨いでください。 その際は，歩きながら100から順々に 7 を引き，口頭 で答えてください。決して立ち止まらずに考え，答え ながら歩いてください。」と口頭指示および検者によ るデモンレーションを十分に行なったのちに実施した。 なお, 認知課題実施の際は, 対象者の隣を検者が歩き, 正解の有無に関わらず答えた数字を記録した。

測定機器は, 三次元動作解析装置 (アニマ社製 : LOCUS IIID MA- 2250) と大型床反力計システム (アニ マ社製：G1812) を使用した。大型床反力計システム と赤外線カメラの位置関係を図 1 に示した。大型床反 カ計システムは, 縦 $250 \mathrm{~cm} \times$ 横 $40 \mathrm{~cm}$ のプレートを 4 枚

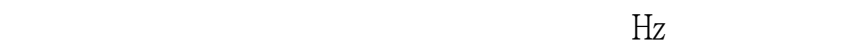
ルコンピュータに記録した。三次元動作解析装置と大 型床反力計システムを同期させ , 大型床反力計システ 厶の Z 軸に2 $5 \mathrm{~kg}$ 以上の質量を感知した時点から10秒 間，三次元動作解析装置が作動するように設定を行っ た。

障害物跨ぎにおける足部の踏み切り位置のつま先と
障害物間との距離である toe-obstacle distance および障 害物を跨いだ後の足部の接地位置の踵部と障害物間と の距離である heel obstacle distance を計測するために， 赤外線発光ダイオード (以下，LED）は，両側母指背 側皮膚上 2 箇所に貼付した。母指背側皮膚上の LED を中心とする半径 $\mathrm{R}$ の円周上に母指先端および足底 位置を定義するため, 安静立位でLED から床までの 垂直距離と LED から母指先端までの距離が等しくな るように位置を調整し，測定前にLED の高さを計測 した。

測定項目は, 歩行速度, 歩幅, 歩行率の歩行パラメー タと toe-obstacle distance および heel-obstacle distance とした。歩行速度, 歩幅, 歩行率は, 大型床反力計シ ステムから $5 \mathrm{~m}$ 歩行所要時間と歩数を求めて算出した。 toe-obstacle の算出方法は, 障害物を跨ぐ際の接地位 置の LED 実測値から半径 R を引いた值とした。heelobstacle distance の算出方法は，障害物を跨いだ直後の LED 実測值から足長を差し引き, 半径 $\mathrm{R}$ を足した值 とした。

統計処理は 対象者の属性の比較には,Kruskal-Wallis の検定を用い, 多重比較には Bonferroni の補正を用い た。障害物を跨ぐ運動課題にて測定した各パラメータ は, 5 回施行の平均值を代表値として, 対象群 (若年 群, 非転倒経験群, 転倒経験群)と歩行条件(ST, DT) について反復測定による二元配置分散分析を用いた。 主効果が有意であった際の下位検定や交互作用が有意 であった際は，Bonferroni の補正を行った。また，DT 認知課題正解数の比較には, Kruskal-Wallis の検定を

大型床反カ計システム

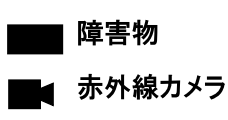

O LED

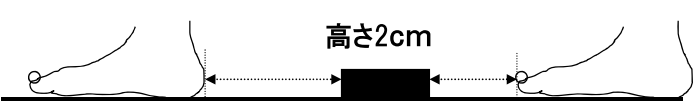

heel-obstacle distance toe-obstacle distance

高さ $2 \mathrm{~cm}$
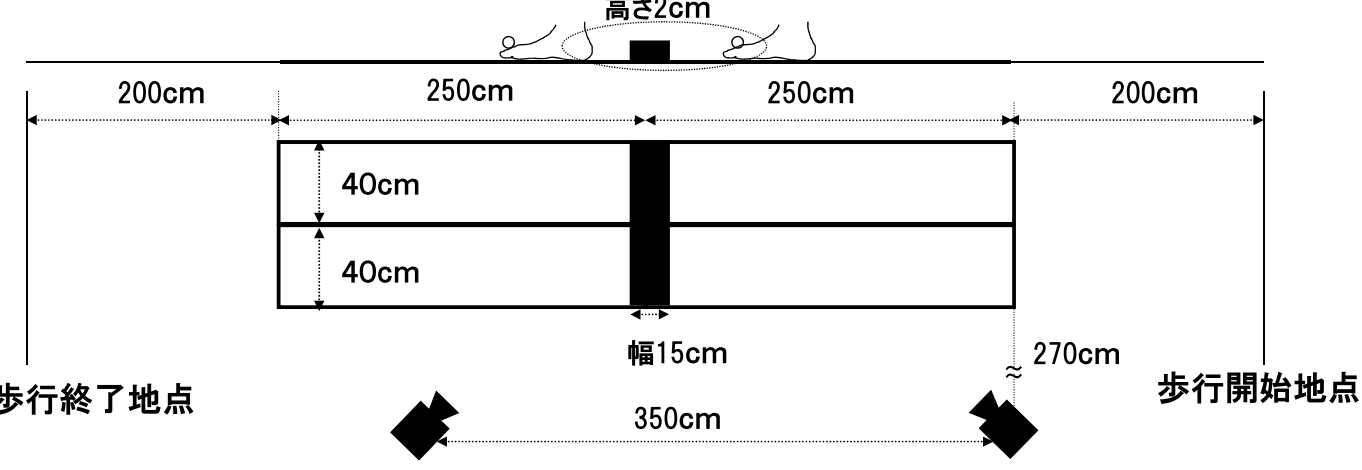

図 1 三次元動作解析装置と床反力計, 障害物との位置関係 
用い，多重比較には Bonferroni の補正を用いた。なお， いずれも有意水準を 5 \%とした (SPSS ver15 .0)。

\section{III. 結 果}

対象者の属性では，年齢および身長に有意な差が認 められた。多重比較の結果 , 年齢は若年者が非転倒経 験群，転倒経験群に比べ有意に低値を示し，身長は， 若年者が非転倒経験群，転倒経験群に比べ有意に高値 を示した ( $<<0$.05) (表 1$)$ 。

障害物を跨ぐ運動課題では，歩行速度が，歩行条件 に有意な主効果が認められた $(\mathrm{F}(1,57)=912, \mathrm{p}$ $<0$.05)。また対象群と歩行条件との間に有意な交互 作用が認められた $(\mathrm{F}(1,57)=3.7, \mathrm{p}<0.05)$ 。多 重比較の結果, DT 条件はST 条件に比へ有意に低値 を示した。歩幅は, 歩行条件および対象群で主効果が 認められた $(\mathrm{F}(1,57)=26.3, \mathrm{p}<0.05),(\mathrm{F}(1,57)$ $=81, \mathrm{p}<0$.05)。多重比較の結果，DT 条件は, ST 条件に比べ有意に低值を示し，対象群間では非転倒経 験群と転倒経験群は若年群に比べ有意に低值を示した。 歩行率は，歩行条件に主効果か認められた $(\mathrm{F}(1,57)$ $=82.9, \mathrm{p}<0$.05)。多重比較の結果, DT 条件は ST 条件に比べ有意に低値を示した。toe-obstacle distance は, 対象群と歩行条件との間に有意な交互作用か認め られた $(\mathrm{F}(1,57)=48, \mathrm{p}<0$.05)。多重比較の結 果，若年群および非転倒経験群の DT 条件は ST 条件 に比へ有意な差か認められなかったものの，転倒経験 群の DT 条件はST 条件に比へ有意に低值を示した。 heel-obstacle distance は, 歩行条件および対象群で主効 果か認められた $(\mathrm{F}(1,57)=7.0, \mathrm{p}<0.05),(\mathrm{F}(1,57)$ $=9.9, \mathrm{p}<0.05)$ 。多重比較の結果, DT 条件は ST 条 件に比へ有意に低值を示し，対象群間では非転倒経験 群と転倒経験群は，若年群に比へ有意に低值を示した

(表 2 )。

$\mathrm{DT}$ 認知課題正解数は, 若年群が3 1土 1 .0問, 非転

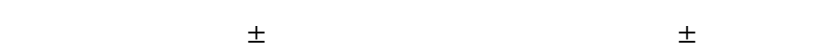
あつた。若年群の正解数は, 非転倒経験群, 転倒経験
群に比べ有意に高值を示した $(\mathrm{p}<0.05)$ 。

\section{N. 考 察}

本結果から，若年群および非転倒経験群と転倒経験 群間では, 歩行速度および障害物を跨ぐ際の踏み切り 位置である toe-obstacle distance に対象群と歩行条件と の間に有意な交互作用か認められた。このことから， 障害物の跨ぐ際の踏み切り位置が各群により異なって いる可能性が示唆された。つまり，DT 条件下におい て障害物を跨ぐ際に，若年群および非転倒経験群は， 歩行速度を減少するものの, toe-obstacle distance を変 化させず障害物を跨いでいることになる。しかし，転 倒経験群は，歩行速度を減少させ，さらに toe-obstacle distance を減少させて障害物を跨いでいることになる。

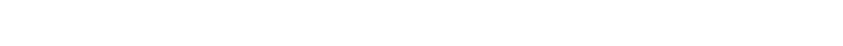
転倒経験群において認知課題を負荷したことが無意識 的に歩行速度と toe-obstacle distance の減少を生じさせ た可能性がある。転倒経験群は，ST 条件下の平地歩 行においても自身の歩行へ向けられる注意量が大きい 割合を占める。光れに加え，DT 条件では認知課題が 負荷されたことから，歩行に向けられる注意量の割合 が減少し，弚の結果として身体の末梢部であるつま先 への注意が低下し, toe-obstacle distance の減少か認め られたことが考えられる。2つ目は，本研究の転倒経 験群では，障害物跨ぎ動作の安全性を高めるために意 図的に，歩行速度と toe-obstacle distance の減少という 方略を用いた可能性がある。Shumway-cook ら ${ }^{25}$ は， 運動課題と認知課題への注意が同時に要求される DT 条件下では，虚弱高齢者が運動課題を優先する posture first strategy を用いることを報告している。このこと を考慮すると転倒経験群は，障害物跨ぎ動作の安全性 を高めるためより近くで障害物を跨ぐ方略を選択して いたことも考えられる。本結果では，無意識的，意識 的に toe-obstacle distance を減少させたのかを明らかに できないものの，今後，検討する必要があると考えら れた。

表 2 障害物跨ぎ課題における各条件下の歩行パラメータ

\begin{tabular}{|c|c|c|c|c|c|c|c|c|c|}
\hline & \multicolumn{2}{|c|}{ 若年群 $(n=30)$} & \multicolumn{2}{|c|}{ 非転倒経験群 $(n=23)$} & \multicolumn{2}{|c|}{ 転倒経験群 $(n=7)$} & \multicolumn{2}{|c|}{ 主効果 } & \multirow{2}{*}{$\begin{array}{c}\text { 交互作用 } \\
\text { 群× 歩行条件 }\end{array}$} \\
\hline & ST & DT & ST & DT & ST & DT & 条件 & 群 & \\
\hline 歩行速度 $(\mathrm{m} / \mathrm{min})$ & $67.6 \pm 92$ & $59.0 \pm 12.0$ & $66.7 \pm 10.5$ & $54.5 \pm 7.6$ & $68.7 \pm 10.5$ & $508 \pm 9.7$ & * & & $* *$ \\
\hline 歩幅 (cm) & $602 \pm 42$ & $581 \pm 5.6$ & $56.7 \pm 6.4$ & $522 \pm 48$ & $56.3 \pm 6.7$ & $508 \pm 48$ & $*$ & $*$ & \\
\hline 歩行率 (steps／min) & $111.9 \pm 109$ & $1011 \pm 141$ & $117.7 \pm 8.7$ & $105.0 \pm 91$ & $1212 \pm 8.6$ & $100.7 \pm 15.9$ & $*$ & & \\
\hline Toe-obstacle distance $(\mathrm{cm})$ & $19.7 \pm 5.4$ & $21.0 \pm 58$ & $21.9 \pm 5.0$ & $218 \pm 43$ & $256 \pm 101$ & $188 \pm 6.0$ & & & $* *$ \\
\hline Heel obstacle distance $(\mathrm{cm})$ & $17.0 \pm 4.6$ & $13.5 \pm 52$ & $124 \pm 52$ & $8.7 \pm 3.4$ & $10.9 \pm 63$ & $113 \pm 51$ & $*$ & $*$ & \\
\hline
\end{tabular}


本研究より，若年群および非転倒経験群と転倒経験 群ともにDT 件下において, 歩行速度, 歩幅, 歩行率 の低下が認められた。Beauchet ら ${ }^{16)}$ は, 平均年齢83.6 歳の虚弱高齢者を対象とし，運動課題を10m歩行，認 知課題を 1- backward としたDT 条件下では，歩行速 度の減少か認められたことを報告している。本研究結 果は，これらの先行研究を支持する結果であった。歩 行速度は, 歩幅, 歩行率と密接に関係していることか ら，歩行速度が遅いために，他のデータの值も影響を 受けたものと思われる。このことから，本研究で用い た快適歩行での障害物跨ぎと連続 7 減算の認知課題の DT 条件下は, 運動課題へ影響を及ぼすことが示され た。これは, 運動課題と認知課題が干渉し, 限りある 注意資源量の中において各群とも歩行への注意量の割 合が減少させることができたと考えられる。また，本 研究の DT 認知課題正解数は, 若年群が非転倒経験群, 転倒経験群より有意に高かったものの，この差異は， 加齢の影響に起因するものと考える。

DT 条件は, 認知機能を身体機能測定値に反映させ る方法であることから，運動課題と認知課題との難易 度によって，反映度が異なると予想される。今回は， 各パラメータの 5 回施行の平均値を用いているため， 連続 7 減算への慣れや学習効果もあったことも推測さ れ，これらのことも踏まえて今後，認知課題の難易度 により動作がどのような影響を受けるのか詳しく調査 する必要があると考えられた。

\section{引用文献}

1 ) David HG, Freedman: Injuries caused by tripping over paving stones: an unappreciated problem . BMJ, 1990, 300: 784-785.

2 ) Campbell AJ, Borrie MJ, Spears GF, et al: Circumstances and consequences of falls experienced by a community population 70 years and over during a prospective study. Age Aging, 1990, 19(2): 136-141.

3 ) Austin GP, Carrett GE, Bohannon RW: Kinematic analysis of obstacle clearance during locomotion. Gait posture, 1999, 10(2): 109-120.

4 ) Chen HC, Ashton-miller JA, Alexander NB, et al : stepping over Obstacles: Gait patterns of healthy young and old Adults. J Gerontol, 1991, 46(6): M196-M203.

5 ) Chou LS, Draganich LF Song SM : Minimum energy trajectories of swing ankle when stepping over obstacles of different heights. J Biomech, 1997, 30(2): 115-120.

6 ) 阿江通良, 岡田英孝, 尾崎哲郎・他 : 高齢者の歩行中のま たぎ越し動作に関する kinematics 的研究 . バイオメカニズ ム, $1999,23(2): 112121$.

7 ) Patla AE, Vickers JN: Where and When do we look as we approach and step over an obstacle in the travel path?. Neuroreport,
1997, 8(17): 3661-3665.

8 ) Chou LS, Draganich LF: Stepping over an obstacle increases the motions and moments of the joints of the trailing limb in young adults. J Biomech, 1997, 30(4): 331-337.

9 ) Chen HL, Lu TW: Comparison of the joint moments between leading and trailing limb in young adults when stepping over obstacle. Gait Posture, 2006, 23(1): 67-77.

10) Mohagheghi AA, Moraes R, PatlaAE: The effects of distant and on line visual information on the control of approach phase and step over an obstacle during locomotion. Exp Brain Res, 2004, 155(4): 459-468.

11) Patla AE, Adkin A, Martin C, et al: Characteristics of voluntary visual sampling of the environment for safe locomotion over different terrains. Exp Brain Res, 1996, 112(3): 513-522.

12) Patla $\mathrm{AE}$, et al: Understanding the contribution of binocular vision to the control of adaptive locomotion. Exp Brain Res, 2002, 142(4): 551-561.

13) Chou LS, Draganich LF: Increasing obstacle height and decreasing toe-obstacle distance affect the joint moments of the stance limb differently when stepping over an obstacle. Gait Posture, 1998, 8(3): 186-204.

14) Lundin-Olsson L, Nyberg L, Gustafson Y: "Stops walking when talking" as a predictor of falls in elderly people. Lancet, 1997, 349: 617 .

15) Beauchet O, Dubost V, Allali G, et al: 'Faster counting while walking' as a predictor of falls in older adults. Aging Ageing, 2007, 36(4): 418-423.

16) Beauchet $O$, Dubost V, Herrmann F, et al: Relationship between dual-task related gait changes and intrinsic risk factors for falls among transitional frail older adults. Aging Clin Exp Res, 2005, 17(4): 270-275.

17) Hollman JH, Kovash FM, Kubik JJ, et al: Age-related differences in spatiotemporal markers of gait stability during task walking. Gait Posture, 2006, 26(1): 113-119.

18) Woolacott M, Shumway-Cook A : Attention and the control of posture and gait: a review of an emerging area of research. Gait Posture, 2002, 16(1): 1-14.

19) Yogev G, Giladi N, Peretz C, et al: Dual tasking, gait rhythmicity, and Parkinson's disease: which aspects of gait are attention demanding? Eur J Nerosci, 2005, 22(5): 1248-1256.

20) Rochester L, Hetherington V, Jones D, et al: The effect of external rhythmic cues (auditory and visual) on walking during a functional task in homes of people with Parkinson's disease. Arch phys Med Rehabil, 2007, 86(5): 999-1006.

21) Schrodt LA, Mercer VS, Giuliani CA, et al: Characteristics of stepping over an obstacle in community dwelling older adults under dual-task conditions. Gait Posture, 2004, 19(3): 279-287.

22) Souma M, Masuda T, Shimamura R, et al: Influence or a dual-task on toe clearance of the young and elderly while stepping over a obstacle. J. Phys. Ther. Sci, 2010, 22(1): 75-79.

23) 鈴木隆雄 : 大腿骨頸部骨折発生の現状と課題. 理学療法, $2004,21(5): 691-699$.

24) Gibson MJ: Falls in later life. NewYork, Oxford University Press, 1990, 296-315. 
25) Shumway-cook, Woollacott M, Kerns KA, et al: The effects of two types of cognitive task on postural stability in older adults with and without a history of fall. J Gerontol A Biol Sci Med Sci, 1997, 52(4): M232-240.

26) 山田実・上原稔章 : 二重課題条件下での歩行時間は転倒の 予測因子となりうる-地域在住高齢者を対象とした前向き 研究一. 理学療法科学, 2007, 22(4) : 505-509.

27) Bootsma-van der wiel A, Gussekloo J, de Craen AJ, et al: Walking and talking as predictors of falls in the general population: The leidn 85-plus study. J Am Greriatr Soc, 2003, 51(3): 14661471.

28) Shumway-cook, Brauer S, Woollacott M: Predicting the probability for falls in community-dwelling older adults using the timed up \& go test. Phys ther, 2000, 80(9): 896-903.

29) Wright DL, Kemp TL: The dual-task methodology and assessing the attentional demands of ambulation with walking device. Phys ther, 1992, 72(4): 306-312. 